\title{
O QUe TEM NO MUSEU PROfessor? PeRCepÇões dos estudantes DO ENSINO MÉDIO SOBRE VISITA AO MUSEU DE CIÊNCIAS
}

\author{
WHAT DO WE HAVE IN THE MUSEUM PROFESSOR? HIGH SCHOOL STUDENTS' \\ PERCEPTIONS ABOUT VISITING THE SCIENCE MUSEUM
}

¿QUÉ HAY EN EL MUSEO DE LA ENSEÑANZA? LA PERCEPCIÓN DE LOS ESTUDIANTES DE SECUNDARIA SOBRE LA VISITA AL MUSEO DE CIENCIAS

\section{Caio Vitor Sales Lima de Oliveira \\ (iD) \\ Graduando em Licenciatura \\ Ciências Biológicas \\ caiovitorsaleslimadeoliveira@gma \\ il.com}

\section{João Paulo Cunha de Menezes \\ (iD) 9}

Doutor em Ciências

Docente no Programa de Pós

Graduação Profissional de Ensino

de Biologia (PROFBIO)

Professor Adjunto do Núcleo de

Educação Científica do Instituto de

Ciências Biológicas na

Universidade de Brasília

joaopauloc@unb.br

\begin{abstract}
Resumo
Os museus são ambientes de aprendizagens não formais populares que são visitados por diferentes sujeitos da sociedade, mas pouco explorado por professores. Neste cenário, este trabalho apresenta como propósito uma reflexão sobre as percepções de estudantes do ensino médio sobre uma visita guiada em dois museus desenvolvidos por licenciandos do Programa Institucional de Bolsa de Iniciação à Docência. Por meio de narrativas produzidas pelos estudantes de ensino médio e analisadas segundo Análise Textual Discursiva foi possível analisar diferentes percepções. Seguindo está metodologia, obtivemos três categorias: Associação com vivências e conhecimentos prévios, Museu como espaço de junção, prática com a teoria e Contribuição do PIBID na visita guiada. Com esse resultado foi possível concluir a importância de se trabalhar em ambientais não formais de ensino como a relevância do projeto no processo de aprendizagem dos estudantes de ensino médio.

Palavras-chave: Educação não formal. Formação inicial docente. PIBID.
\end{abstract}

Recebido em: 11 de janeiro de 2021.

Aprovado em: 14 de abril de 2021.

Como citar esse artigo (ABNT):

OLIVEIRA, Caio Vitor Sales Lima de; MENEZES, João Paulo Cunha de. O que tem no museu professor? Percepções dos estudantes do ensino médio sobre visita ao museu de ciências. Revista Prática Docente, v. 6, n. 1, e 022, 2021. http://doi.org/10.23926/RPD.2021.v6.n1.e22.id967 


\begin{abstract}
The museums are popular non-formal learning environments that are visited by different subjects of society, but less explored by teachers. In this scenario, this paper presents purpose a reflection on the perceptions of high school students about a guided tour in two museums developed by undergraduate students in the Institutional Program for Scholarship Initiation to Teaching. Through narratives produced by the high school students and analyzed according to Textual Discourse Analysis, it was possible to analyze different perceptions. Following this methodology, we obtained three categories: Association with experiences and previous knowledge, Museum as a space of junction, practice with theory, and PIBID's contribution in the guided visit. With this result, it was possible to conclude the importance of working in non-formal educational environments as the relevance of the project in the learning process of high school students.
\end{abstract}

Keywords: Non-formal education. Initial teacher training. PIBID.

\section{Resumen}

Los museos son entornos populares de aprendizaje no formal que son visitados por diferentes sujetos de la sociedad, pero poco explorados por los profesores. En este escenario, este trabajo presenta como propósito una reflexión sobre las percepciones de los estudiantes de secundaria sobre una visita guiada en dos museos desarrollada por estudiantes del Programa Institucional de Becas de Iniciación a la Docencia. A través de las narraciones producidas por los estudiantes de secundaria y analizadas según el Análisis Textual del Discurso fue posible analizar las diferentes percepciones. Siguiendo esta metodología, obtuvimos tres categorías: Asociación con experiencias y conocimientos previos, Museo como espacio de confluencia, práctica con teoría y aportación de PIBID en la visita guiada. Con este resultado se pudo concluir la importancia del trabajo en entornos educativos no formales como la relevancia del proyecto en el proceso de aprendizaje de los estudiantes de secundaria.

Palabras clave: Educación no formal. Formación inicial del professorado. PIBID. 


\section{INTRODUÇÃo}

A educação é direito de todos os cidadãos, reconhecida pela legislação devendo ser apresentada como forma de preparo para o futuro, propiciando oportunidades de crescimento das pessoas de forma ativa em um contexto social participativo (GADOTTI, 2005). No entanto, a educação formal não consegue desenvolver este papel de forma efetiva de modo que a educação não formal pode servir de complemento no processo de aprendizagem (VIEIRA; BIANCONI; DIAS, 2005).

Gohn (2006) define como educação não formal aquela em que os indivíduos aprendem durante um processo natural de socialização, podendo ocorrer em diversos locais que o mesmo frequenta, tendo como agentes educadores os pais, colegas, vizinhos, outros e ocorre de forma espontânea. Affeldt et al. (2017) acrescenta que a aprendizagem não formal refere à aprendizagem que normalmente ocorre fora do ambiente escolar tradicional, não apresentando uma estrutura e não segue um currículo específico. Além disso, a aprendizagem não formal é voluntária e ocorre principalmente nas horas de lazer dos estudantes (PRASETYO; SURYONO; GUPTA, 2021). Nesta perspectiva, a educação não formal apresenta-se como uma alternativa e/ou um complemento à educação formal dentro do processo de ensino e aprendizagem ao longo da vida dos estudantes e demais indivíduos da sociedade, contemplando pessoas de todas as idades, podendo ser de curta duração e /ou baixa intensidade. A educação não formal pode abranger programas que contribuam para a alfabetização de científica dos indivíduos, bem como desenvolvimento social ou cultural (DEBARLIEV et al., 2020).

Nesse cenário se encaixam os museus de ciências; sobre estes espaços, Marandino et al. (2005) afirma que atualmente é indiscutível a importância dos museus no que diz respeito à popularização e divulgação da ciência tornando as informações apresentadas acessíveis ao público. A consolidação do papel educativo que o museu possui ocorre por meio da diversificação do público, não contendo apenas em expor obras (MARANDINO, 2008). Neste contexto, os museus ao assumir o papel de divulgação do conhecimento à sociedade, também assume a "sociedade" como seu público alvo. E, uma vez assumindo que esse é representado pela sociedade, as estratégias para divulgação do museu podem ser interpretadas como mecanismos de comunicação. Esta comunicação é importante no contexto de sala de aula, uma vez que estes espaços instigam a curiosidade dos estudantes, estimulando um pensamento crítico (QUEIROZ et al., 2017). 
Conhecendo o papel que os museus oferecem dentro dos espaços não formais, vale destacar acerca da pedagogia museal; sendo elas: lugar, tempo e importância do acervo (MARANDINO, 2005). Com relação ao lugar, destaca-se o fato de o museu ser considerado um espaço aberto que contrapõe ao espaço da escola. Neste aspecto, é importante que o professor e o mediador organizem o tempo com o intuito de evitar o cansaço dos estudantes. O tempo em relação ao tempo escolar é considerado breve, ponderando os minutos que um estudante gasta para observar cada objeto determinado pelo mediador. Não menos importante, para referir ao aspecto dos objetos, os estudantes podem se sensibilizar, se apropriar e favorecer sua compreensão para uma análise pessoal (MARANDINO, 2005).

Um dos elementos chaves para poder trabalhar no contexto de espaços não formais é o processo de mediação e organização. Neste contexto, ainda nos deparamos com professores com dificuldade em se adaptar a um novo ambiente, um certo receio de expandir o conhecimento para fora da sala de aula, como fazer passeios em determinados lugares. Para Martins (2012), a principal função de um mediador é instigar os estudantes em diferentes formas de percepção. Desta forma, esses profissionais precisam desenvolver habilidades pedagógicas intencionais. Tais habilidades constituem-se a partir de um processo, que tem início com o seu contato introdutório com o acervo de forma a permitir a maior experiência possibilitando a organização de estratégias. No entanto, "o fato de atuar no setor educativo, seja em instituições culturais ou escolares, não faz desse profissional um mediado" (URIARTE; ZDRADEK; 2021, p.121).

Neste contexto, o Programa Institucional de Bolsa de Iniciação à Docência (PIBID) pode contribuir com esses docentes em formação. O PIBID é um programa financiado e idealizado pela Coordenação de Aperfeiçoamento de Pessoal de Nível Superior do Brasil que procura contribuir com a formação de professores, em todas as áreas, por meio da concessão de bolsas para estudantes das licenciaturas, articulando uma relação entre a universidade e a escola, envolvendo os professores da escola pública na função de staff desses acadêmicos oriundos das licenciaturas.

Por meio de mudanças metodológicas do professor staff ${ }^{1}$ no caminhar do desenvolvimento do programa, em conjunto com um docente da universidade e com os licenciados, oportuniza aprendizagem para todos os envolvidos (NÓVOA, 1992). Desta forma,

\footnotetext{
${ }^{1}$ Professor staff refere-se ao professor supervisor: o docente da escola de educação básica das redes públicas de ensino que integra o projeto institucional, responsável por acompanhar e supervisionar as atividades dos bolsistas de iniciação à docência.
} 
o PIBID permiti a união da produção do conhecimento da universidade com o conhecimento advindo da prática dos professores das escolas públicas. Esta união, pode fornecer ao professor da educação básica uma formação continuada do professor staff.

Silva (2017) trabalhando em um museu com o PIBID observou que, a realização de visitas, no âmbito do PIBID - Química teve contribuições significativas com a formação docente de modo a explorar novas oportunidades e potencialidades desses espaços. A autora acrescenta que o PIBID tem criado condições para os estudantes possam experienciar diferentes estratégias no campo de formação de professores. Tempesta e Gomes (2017) adicionam que, as contribuições de trabalhar educação não formal em museu por meio do PIBID vão além do esperado, revelando um potencial para à formação inicial, contribuindo para o desenvolvimento de competências e habilidades que hoje se exige dos professores e lhes proporcionando uma carga de experiências que de outra forma não seria possível.

Devido à importância deste tema, o PIBID de Biologia desenvolveu uma excursão guiada no ano de 2019, com alunos do ensino médio da rede pública de educação de Brasília. Assim, o objetivo do presente trabalho foi avaliar as percepções que os estudantes de ensino médio possuem sobre a observação dos objetos museológicos vivenciados pelo grupo durante uma visita guiada em dois museus da Universidade de Brasília desenvolvida por licenciandos do Programa Institucional de Bolsa de Iniciação à Docência.

\section{Procedimentos do MÉtodo}

Esse trabalho caracteriza-se como uma pesquisa qualitativa, com embasamento em Narrativas de Vivências de 41 estudantes do ensino médio de uma escola pública de Brasília. O grupo de estudante apresentada idade variando entre 14 e 17 anos, composto por 18 homens e 23 mulheres. A narrativa como um método de investigação, permite-nos aderir ao pensamento experiencial dos estudantes, assim como aderir às situações vividas, dando uma informação situada do que se está a investigar (GALVÃO, 2005). Todo trabalhado foi desenvolvido por meio das experiências vivenciados pelos estudantes do PIBID Ciências da Natureza/Biologia.

A visitação guiada ocorreu aos seguintes órgãos de divulgação científica e tecnológica da Universidade de Brasília: o Museu de Anatomia Humana da Faculdade de Medicina da Universidade de Brasília (MAH) e o Museu de Geociências (MGE), no final do ano de 2019. Nessa oportunidade, os estudantes do ensino médio participaram de visitações interativas no salão de exposições de ambos locais. A visitação ocorreu da seguinte forma: inicialmente, os estudantes foram divididos em grupos menores (10) onde foram apresentados ao museu pelos 
monitores do espaço; em seguida, o grupo teve liberdade para interagir com alguns dos objetos museológicos do espaço; por fim, os estudantes reuniram-se em um espaço aberto da Universidade de Brasília (pilotis da botânica) para dialogar sobre o papel do museu no que tange a divulgação científica. Após discussão, como instrumento pedagógico para a reflexão individual dos integrantes do grupo, sugeriu-se que os mesmos escrevessem em uma carta aquilo que achavam importante ao longo da visitação aos museus.

As cartas produzidas constituem um conjunto de narrações que refletem as observações e reflexões dos estudantes, sendo estes os instrumentos de coleta de dados escolhidos. De forma a adequar o presente trabalho aos preceitos éticos da pesquisa, os estudantes que aceitaram participar da visita à universidade e da pesquisa assinaram de livre e espontânea vontade um Termo de Consentimento Livre e esclarecido. Os participantes da pesquisa foram denominados com a sigla E. (estudante) seguido de um número (1 a 41).

Utilizou-se como método de categorização das informações coletadas a Análise Textual Discursiva (MORAES; GALIAZZI, 2007). A Análise Textual Discursiva é determinada por um processo de auto-organização textual na construção de compreensão em que novos entendimentos surgem a partir de três componentes sequenciais: (i) unitarização; (ii) categorização; e (iii) captação emergente (MORAES; GALIAZZI, 2007). A interpretação na desta análise pode ser feita por diferentes formas. Neste trabalho, essa interpretação foi feita a partir das narrativas produzidas, por semelhança e diferença, e da comparação entre as informações contidas. Assim, foram estabelecidas pontes entre os materiais analisados e os objetivos de pesquisa por meio da Análise Textual dentro das três categoriais determinadas: i) Associação com vivências e conhecimentos prévios; ii) Museu como espaço de junção, prática com a teoria e iii) Contribuição do PIBID na visita guiada.

\section{RESUlTADOS E DISCUSSÕES}

Seguindo está metodologia, obtivemos três categorias: Associação com vivências e conhecimentos prévios, Museu como espaço de junção, prática com a teoria e Contribuição do PIBID na visita guiada.

\subsection{ASSOCIAÇÃO COM VIVÊNCIAS E CONHECIMENTOS PRÉVIOS}

Avaliamos que a visita aos acervos dos museus é sempre uma oportunidade rica, autêntica e cheia de aprendizados significativos que difere de um ambiente formal de ensino. 
Esta avaliação pode ser observada pelas narrativas, podendo ser exemplificada na percepção dos estudantes descritos abaixo:

"[...] o meu pai é fumante, será que o pulmão dele esta desta forma?" (E.34, em referência a visualização de um pulmão de fumante)

"Esta pedra é a mesma que minha mãe usa em teu anel... é perola mesmo?" (E.40)

As falas dos estudantes aparecem durante toda a visita associada às temáticas do acervo com relação às vivências pessoais de cada estudante, tais como conhecimentos aprendidos em sala de aula, vivências pessoais, culturas e outros. Essas relações vão ao encontro do que Cury (2011) propõem ao colocar que, em um modelo emergente de museu, o objetivo de uma visita pode ser múltiplo e atrelado a uma vivência que se propõem, contrapondo ao modelo tradicional de ensino que objetiva a obtenção do conhecimento. Desta forma, o museu estimula a produção de novos significados, valorizando a subjetividade e as relações intersubjetivas que acontecem em seus espaços. Entendemos que a visita ao museu pode ser um importante momento de formação, no entanto, ainda pouco explorado por professores do ensino público no Brasil.

Ainda pensando na avaliação das experiências pedagógicas desenvolvidas nos museus propostos pelo grupo do PIBID Biologia, observamos que na vivência predominam relações de assimilação sobre os temas propostos em cada museu, com relação à transposição nas explicações que os monitores estimulam durante o percurso. Também vale ressaltar que, as relações de transposições refletidas nas conversas dos licenciandos participantes do projeto PIBID com os estudantes do ensino médio sobre os conteúdos contribuem para a contextualização do conhecimento. No entanto, relações de suporte menos presentes centramse na orientação espacial do museu como em normas de comportamento, o que pode gerar percepções negativas nos estudantes (MASSARANI et al., 2019).

A aprendizagem ativa de ciências, na qual o estudante está envolvido, investiga e experimenta as relações entre ciência, tecnologia e sociedade é extremamente importante em contextos formais e informais (TAL; MORAG, 2007). Voltando ao modelo de aprendizado, foi observado uma alta referência aos licenciandos do PIBID das experiências dos próprios estudantes, com uso aprofundado da exposição e com algum grau de oportunidade para interações sociais dentro do grupo e com outras pessoas. Para Massarani et al. (2020) a visita ao museu pode potencializar a visão crítica do contexto sobre assuntos concernentes às temáticas discutidas nos acervos e exposições como também auxilia na interpretação do contexto econômico, social, local e global. Acreditamos que esta realidade aqui descrita é relevamento mesmo além dos museus. 
Nossas observações convergem com as observações realizadas por Massarani et al. (2019). Esses autores sugerem que, quando estudantes frequentam museu, estes podem vivenciar diversas experiências que possibilita tornar este espaço oportuno para uma aprendizagem efetiva e trazer a discussão sobre a ciência que os tangenciam. A "visita ao museu proporciona um aprendizado mais significativo dos conteúdos, pelo contato com os mesmos de forma concreta e prática (BLANCO; ARAÚJO; COELHO NETO, 2017, p. 289)”".

\section{Museu como espaço de junção, prática com a teoria}

Por meio das narrativas apresentadas pelos estudantes foi possível observar que os mesmos analisaram os museus como um local que preza pela relação das práticas com a teoria. Essa ideia pode ser exemplificada na percepção de alguns dos estudantes, descrita abaixo:

\footnotetext{
"Ambiente maravilhoso, a explicação foram todas bem claras, deu pra vê como é o corpo bem detalhados, me senti bem a vontade pois perguntei tudo e tirei todas as dúvidas que tinha quando vi a disciplina em sala de aula, além de ser um ambiente fresco e bem organizado." (E.2)

"Na área de geologia podemos ver fósseis de muitos anos atrás, pedras valiosas que particularmente eu nunca tinha visto a não ser no livro didático e achei interessante. A escola poderia trabalhar esses conhecimentos na prática". (E.13)

"No museu de Geociências tivemos a oportunidade de ver pedras preciosas e a forma delas de antes e depois de serem lapidadas. Muito bom ver o que está no livro, mas na prática, auxilia a compressão da matéria". (E.18)
}

As falas dos estudantes se conectam com o que Loughran (2006) ressalta em tua pesquisa que, a prática pedagógica em ambiente de condição "real" é extremamente importante na formação inicial. Este modelo consiste em competências que não podem ser adquiridas ou desenvolvidas de nenhuma outra forma senão em um ambiente autêntico e real. Tais competências são, por exemplo, aplicação de metodologias didática, gerenciamento de atividades educacionais, auto regulação, entre outras (KRELOVÁ; KRPÁLEK; DVORAK 2013). Ainda sobre a importância da teoria em junção com a prática, Saviani (2007) adiciona que, a teoria e prática são aspectos dialeticamente distintos e fundamentais nas experiências dos alunos, definindo-se um em relação ao outro: a prática é a razão de ser da teoria, o que significa que a teoria só pode ser constituir e só desenvolve em função da prática que opera.

Com relação às percepções que os estudantes possuem, podemos apontar que a observação da teoria vista em sala de aula em uma prática pedagógica possibilitou uma maior contextualização. Nesse processo, o PIBID possibilitou novas oportunidades de vivências e práticas aos estudantes do ensino básico. A junção entre a prática pedagógica ofertada pelos licenciandos do PIBID com a teoria trouxe nos estudantes elementos positivos ao possibilitarem que os mesmos pudessem confrontar a observação com a teoria. Com estas observações, é 
possível afirmar que a visita acabou facilitando a fixação do conhecimento desenvolvido em sala de aula. Essa observação é explícita na fala de um dos estudantes:

“[...] após a visita no museu eu consegui compreender melhor o conteúdo de anatomia que o professor estava explicando na aula. Ficou mais claro tudo que eu estava vendo na aula de biologia[...]". (E.33)

Como pode ser observado, a prática pedagógica tem um papel importante na qualidade do ensino. Assim, pode-se salientar a importância do uso do museu como espaço não formal de aprendizagem, especial em relação às atividades práticas e o contato ao conhecimento científico (SULZBACH; JOHANN, 2021). Desta forma, os estudantes devem dominar não apenas os princípios básicos, mas também os princípios pedagógicos. Assim, a experiência da visitação aos museus auxiliou na relação teoria-prática para tratar temas diversos. Assim, os museus apresentaram-se como centros de aprendizagem onde os estudantes puderam interagir com interesses e saberes desenvolvidos em sala de aula. Sendo estes um importante espaço de vivências e oportunidades concretas de criação de significados.

Alves et al. (2020) analisando o ensino de química e geográfica nos espaços não formais de ensino observou ganhos no processo de ensino e aprendizagem relacionando a junção da teoria com a prática. Quando se trata de elucidar a importância desses espaços não formais nas aulas de química os autores observaram que o museu apresenta-se como um espaço de ensino importante, exercendo a função de facilitar a divulgação do conhecimento além de ser um instrumento didático para diversas áreas de conhecimento.

Mendes e Barbosa (2020) acrescenta que o conhecimento não deve ser restrito a um "campi" onde são gerados, mas se expandir para a comunidade em uma relação dialética na qual o discente tem a oportunidade de vivência a teoria e a prática. Essas possibilidades contribuem para a formação acadêmica e cidadã dos estudantes. Esse cenário foi observado a partir da realidade do Parque Zoobotânico do Museu Paraense Emílio Goeldi, no qual associa teoria e prática ao proporcionar aos frequentadores uma visita responsável para além da contemplação.

\subsection{CONTRIBUIÇÃo do PIBID NA VISITA GUIADA}

Por meio da análise de textual dos relatos desenvolvidos pelos estudantes, destacamos a contribuição do PIBID percebidos pelos sujeitos dessa pesquisa como sendo um elo importante na relação da atividade desenvolvida. Os pibidianos tiveram um papel importante no despertar interesse nos estudantes e repassar o conhecimento ao grupo. 
"Foi uma ótima experiência para mim, gostei muito do acolhimento que os estudantes do PIBID ... gostei muito dessa visita e agradeço a oportunidade que o programa deu para os estudantes da rede publica ... a apresentação e comentários do grupo do PIBID facilitou muita minha compreensão do tema, como também me motivou a prestar maior atenção no acervo..." (E.8)

A percepção do E.8 também foi observada em outros estudantes:

“[...] foi muito mais fácil entender o que os alunos do PIBID falaram do que quando o professor explica em sala de aula [...]” (E.31)

“[...] a forma que o monitor (aluno do PIBID) explica é mais simples, como também me parece mais real, é perceptível que este aluno gosta do que faz ... considero agora fazer um curso da área da saúde [...]” (E.35)

Podemos observar pelas narrativas acima a relação positiva da interação dos licenciandos do Programa Institucional de Bolsa de Iniciação à Docência como os estudantes do ensino médio apresentando um laço afetivo nas experiências vivenciadas nos museus, proporcionando maior interesse nos mesmos. Segundo Ribas et al. (2018), a tendência de aliar atividades educativas e afetivas podem contribuir para uma aprendizagem mais efetiva, mostrando o conhecimento científico como fruto do raciocínio lógico e também dos valores construídos durante a formação escolar. Os sentimentos, emoções e sensações envolvidas no processo educacional podem influenciar de forma significativa na aprendizagem como também na construção de valores.

Para Shaby et al. (2019), usar aspectos motivacionais na apresentação e instrução no museu pode envolver os estudantes com as exposições. Aspectos motivacionais é um termo amplo que se refere a curiosidade, interesse, percepções e valores. Além disso, o envolvimento emocional baseia-se em sentimentos, orientações inerentes ao processo de aprendizagem (MARTIN et al., 2016). Esse tipo de atividade é importante, conforme observado em alguns estudos, têm apresentado que "emoções durante uma atividade pedagógica" (como as que foi desenvolvida neste trabalho) provavelmente geram resultados como maior interesse no ensino de ciência (ITZEK-GREULICH; VOLLMER, 2017). Martin et al. (2016), por exemplo, demonstraram como os elementos emocionais no ambiente levam ao envolvimento emocional dos estudantes durante a visita. Por isso, sugerimos a que o envolvimento emocional deva ser levado em consideração ao desenvolver material de aprendizagem informal.

Outro ponto importante a se destacar é a relação entre pares (no caso, Pibidianos com estudantes) no processo de assimilação neste grupo. É por meio dos diálogos entre os licenciandos (PIBID com estudantes de ensino médio) que são formadas novas relações de conhecimento no qual podem emergir reflexões diversas (MASSARANI et al., 2019). O papel que os licenciandos do projeto do PIBID desempenharam nas interações com os estudantes, 
antes de tudo, foi um papel mais "técnico". Este papel assumido devido a percepção dos pibidianos que os estudantes do ensino médio não saberiam desenvolver a visita sozinhos. Alguns trabalhos têm demostrado que os monitores (neste caso representado pelos pibidianos) são treinados para uma visita direcionada a uma exposição e que o aprendizado não ocorrerá a menos que os visitantes desenvolvam o percurso de forma correta (ASH, 2012; SHABY et al., 2019). Neste contexto, os estudantes parecer perceber o importante papel dos alunos do PIBID, dessa maneira, iniciando uma interação para perguntas sobre a exposição.

A realidade que a educação básica no Brasil tem passado, ainda está longe de um modelo ideal de excelência recomendável. No entanto, vale destacar que iniciativas como o Programa Institucional de Bolsa de Iniciação à Docência visam alcançar níveis melhores para o ensino. Segundo alguns autores (TANAKA; RAMOS; ANIC 2013), o PIBID é um dos programas mais relevantes à educação básica atualmente. Ao propiciar uma aproximação da universidade com a escola pública, ambas transformam: o jovem docente adquire competências e experiências e a escola é estimulada a novos práticas pedagógicas.

\section{CONSIDERaÇões FinaIS}

Nota-se a importância do uso de espaços não formais de educação, visto que são espaços que acrescentam conceitos significativos na formação dos estudantes. Por meio das percepções dos estudantes contidas em suas narrativas, podemos considerar que o museu como espaço não formal de ensino se mostrou um espaço que valoriza o conhecimento sendo um excelente local para aliar a teoria vista em sala de aula com a prática. $\mathrm{O}$ resultado disto é que os visitantes conseguem assimilar melhor o conhecimento científico, aliando a teoria com a prática. Quanto aos benefícios do PIBID, foi verificado por meio das narrativas que o projeto contribui para a formação dos estudantes de educação básica, melhorando a assimilação dos conteúdos. O PIBID pode contribuir para maior participação e interesse dos estudantes pelas atividades, como também favorecer o processo de aprendizagem, beneficiando a relação interpessoal e desenvolvimento do grupo. Essas contribuições podem ser consideradas benéficas não apenas aos estudantes do ensino básico, mas também aos estudantes de licenciatura engajados no programa.

\section{REFERÊNCIAS}

AFFELDT, Fiona et al. The potential of the non-formal educational sector for supporting chemistry learning and sustainability education for all students-a joint perspective from two 
cases in Finland and Germany. Chemistry Education Research and Practice, v. 18, n. 1, p. 13-25, 2017.

ALVES, Dilce dos Santos et al. Educação em espaços não formais: química e geografia-da sala de aula para o museu de solos de Roraima. Revista Insignare Scientia-RIS, v. 3, n. 2, p. 237-256, 2020.

ASH, Doris; RAHM, Jrène; MELBER, Leah M. (Ed.). Putting theory into practice: Tools for research in informal settings. Springer Science \& Business Media, 2012.

BLANCO, Marilia Bazan; ARAÚJO, Roberta Negrão; COELHO NETO, João. Visita ao museu de anatomia como estratégia para a aprendizagem significativa dos conteúdos de neurociência. Vivências, v. 13, n. 25, 2017.

CURY, Marília Xavier. Museus em transição. Museus: o que são, para que servem?, 2011.

DEBARLIEV, Stojan et al. What can education bring to entrepreneurship? Formal versus non-formal education. Journal of Small Business Management, p. 1-34, 2020.

GADOTTI, Moacir. A questão da educação formal/não-formal. Sion: Institut Internacional des Droits de $1^{\circ}$ Enfant, p. 1-11, 2005.Galvão, C. (2005). Narrativas em educação. Ciência \& Educação (Bauru), v. 11, n. 2, 327-345.

GOHN, Maria da Glória. Educação não-formal, participação da sociedade civil e estruturas colegiadas nas escolas. Ensaio: avaliação e políticas públicas em educação, v. 14, n. 50, p. 27-38, 2006.

ITZEK-GREULICH, Heike; VOLLMER, Christian. Emotional and motivational outcomes of lab work in the secondary intermediate track: The contribution of a science center outreach lab. Journal of Research in Science Teaching, v. 54, n. 1, p. 3-28, 2017.

KRELOVÁ, K. K., KRPÁLEK, P., DVORAK, D. Pedagogical Practice and its Significance for Future Teachers. International Journal of Education and Information Technologies, $v$. 2, n. 7, p. 62-71, 2013.

LOUGHRAN, John. A response to 'Reflecting on the self'. Reflective Practice, v. 7, n. 1, p. 43-53, 2006.

MARANDINO, Martha. A pesquisa educacional e a produção de saberes nos museus de ciência. História, Ciências, Saúde-Manguinhos, v. 12, p. 161-181, 2005.

MARANDINO, Martha. Educação em museus: a mediação em foco. 2008.

MARTIN, Andrew J. et al. The role of a museum-based science education program in promoting content knowledge and science motivation. Journal of Research in Science Teaching, v. 53, n. 9, p. 1364-1384, 2016. 
MARTINS, Mirian Celeste. Expedições instigantes. In: MARTINS, Mirian Celeste; PICOSQUE, Gisa.(Org.). Mediação cultural para professores andarilhos na cultura. São Paulo: Intermeios, 2012a. p. 9-22.

MASSARANI, Luisa et al. A experiência de adolescentes ao visitar um museu de ciência: um estudo no museu da vida. Ensaio Pesquisa em Educação em Ciências, v. 21, 2019.

MASSARANI, Luisa et al. A experiência de adolescentes ao visitar um museu de ciência: um estudo no museu da vida. Ensaio Pesquisa em Educação em Ciências (Belo Horizonte), v. 21, 2019.

MASSARANI, Luisa et al. O olhar dos adolescentes em uma visita ao Museo Interactivo de Economía (MIDE), México. Revista CTS, nº 44, v. 15, 2020.

MENDES, Fabricio Lemos de Siqueira; DE ALMEIDA, Helena Doris Barbosa. Visitas monitoradas ao Museu Paraense Emílio Goeldi, Belém-PA, Brasil. Revista Em Extensão, v. 19, n. 2, p. 250-265, 2020.

MORAES, Roque; CARMO GALIAZZI, Maria. Análise textual: discursiva. Editora Unijuí, 2007.

NÓVOA, António. Os professores e a sua formação. Lisboa. Publicações Dom Quixote, 1992.

PRASETYO, Iis; SURYONO, Yoyon; GUPTA, Sachin. The 21st Century Life Skills-Based Education Implementation at the Non-Formal Education Institution. Journal of Nonformal Education, v. 7, n. 1, 2021.

QUEIROZ, Ricardo et al. A caracterização dos espaços não formais de educação científica para o ensino de ciências. Revista Areté| Revista Amazônica de Ensino de Ciências, v. 4, n. 7, p. 12-23, 2017.

RIBAS, Noelle Diniz et al. A importância do espaço de ensino não formal na sensibilização de estudantes durante estudo do tema água. Experiências em Ensino de Ciências, CuiabáMT, v. 13, n. 2, p. 52-61, 2018.

SAVIANI, Dermeval. Pedagogia: o espaço da educação na universidade. Cadernos de pesquisa, v. 37, n. 130, p. 99-134, 2007.

SHABY, Neta; BEN-ZVI ASSARAF, Orit; TAL, Tali. An examination of the interactions between museum educators and students on a school visit to science museum. Journal of Research in Science Teaching, v. 56, n. 2, p. 211-239, 2019.

SILVA, Camila Silveira. Impressões de pibidianas (os) em química sobre a experiência de visitar o museu catavento. O PIBID na UFPR: Socializando Experiências, p. 43, 2017.

SULZBACH, Angelica; JOHANN, Liana. Avaliação do uso do Museu de Ciências Univates como espaço não formal de ensino por professores de escolas públicas e particulares. Revista Brasileira De Educação Ambiental (RevBEA), v. 16, n. 1, p. 09-22, 2021. 
TAL, Tali; MORAG, Orly. School visits to natural history museums: Teaching or enriching?. Journal of Research in Science Teaching: The Official Journal of the National Association for Research in Science Teaching, v. 44, n. 5, p. 747-769, 2007.

TANAKA, Ana Lúcia Drumond; RAMOS, Ribamar Alves; ANIC, Cinara Calvi. Contribuições do PIBID para o ensino de ciências: Ação-Reflexão-Ação em uma escola pública de Manaus/Am. Revista Práxis, v. 5, n. 9, 2013.

TEMPESTA, Azizi Manuel; GOMES, Luciano Carvalhais. Contribuições de um museu de ciências para a formação docente em física. Investigações em Ensino de Ciências, v. 22, n. $1,2017$.

URIARTE, Mônica Zewe; ZDRADEK, Ana Carolina Sampaio. Mediação cultural: construção de sentidos ético-estéticos na educação não-formal. ETD-Educação Temática Digital, v. 23, n. 1, p. 117-134, 2021.

VIEIRA, Valéria; BIANCONI, M. Lucia; DIAS, Monique. Espaços não-formais de ensino e o currículo de ciências. Ciência e Cultura, v. 57, n. 4, p. 21-23, 2005.

\section{Agradecimentos}

Gostaria de primeiramente agradecer a instituição financiadora CAPES que em parceria com a Universidade de Brasília disponibilizou bolsas e permitiu que estudantes da graduação pudessem ter um contato maior com a educação pública. Também agradeço a professora Zara Guimarães, pela orientação durante o projeto, pelas valiosas contribuições dadas durante todo o processo e por nos manter motivados durante todo programa. Aos colegas do PIBID gostaria de agradecer, por ajudar na construção do conhecimento e pela parceira durante as atividades desenvolvidas no programa. Gostaria de agradecer aos alunos de ensino médio por se disponibilizarem a irem para a Universidade para a visitação aos museus. 